\title{
Impact of Experiential Learning on Performance of Students and attainment of Course and Program outcome
}

\author{
S R Nikam ${ }^{1}$, S. S. Bhusnoor ${ }^{2}$ \\ V B Bhosle ${ }^{3}$, A S Saraf ${ }^{4}$ \\ 1,2, 3,4 Mechanical Department, K J Somaiya College of Engineering, Mumbai \\ ${ }^{1}$ shailesh.n@somaiya.edu \\ ${ }^{2}$ siddappabhusnoor@somaiya.edu \\ ${ }^{3}$ vijaybhosale@somaiya.edu \\ 4atul.saraf@somaiya.edu
}

\begin{abstract}
Present paper reports effect of experiential teaching learning method on performance of students. In order to involve student in teaching learning process visit to research laboratory at IIT Bombay was arranged and knowledge gained through this visit is assessed through presentation, group discussion and quiz. Student feedback for self assessment is also taken. It has been observed that this teaching learning method helped students to understand course in better way which is confirmed from their internal assessment as well as in end semester examination result. Also from students self assessment feedback it is noted that their level of understanding in a given topic has improved. This experiential learning method helped in increasing attainment level of Course outcome and related Program outcome.
\end{abstract}

Keywords: Experiential learning, Course outcome, Program outcome.

\section{Introduction:}

In engineering education, engineers are trained in particular discipline to work in industry for serving society. These days, colleges get feedback from industry stating that engineering graduates are not capable or less competent to work in industry immediately after their graduation. They also mention that they are lagging in fundamental knowledge. In present electronic world keeping student actively engaged in the classroom is big challenge. To overcome this problem, there are various innovative

\section{Corresponding Author}

Mechanical Department, K. J. Somaiya College of Engineering, Mumbai.

shailesh.n@somaiya.edu

Teaching learning and assessment tools tried by many teachers [1, 2, 3 and 4] which worked remarkably for enhancing the understanding and interest of students in that course. These days, institutes are focusing more on application based teaching and training approaches which makes every individual learner actively involved in the course. Experiential learning [5, 6, and 7] plays very vital role in understanding the subject and for lifelong learning. Experiential learning supports and acknowledges theories/theoretical knowledge presented in the course. The aim of this paper is to examine the impact of experiential learning on student's academic performance and subsequently on Course outcome (CO) and Program outcome (PO). Present paper reports such experiential learning in one of the course through visit to research laboratory. Students are actively involved during the visit and understanding level is assessed through presentation and group discussion on the system/topic which they have seen/experienced during their visit.

\section{Methodology:}

Present study is carried out at K J Somaiya College of engineering in Mechanical Engineering department for the course Cryogenics. Course outcome for this course are given bellow.

After successful completion of the course student will be able to

i. Explain historical developments and applications in cryogenic systems.

ii. Analyse gas liquefaction and purification systems/methods.

iii. Analyze performance of cryocoolers.

iv. Understand storage and measurement systems 
used in cryogenics.

Visit to Cryogenics laboratory at IIT Bombay was arranged for experiential learning. Various cryogenic systems like, liquefaction system, cryocoolers, storage vessel, insulations are practically seen. Experimental set up for different applications of cryogenics is also studied during visit. All research setup are explained and demonstrated by research scholars in the laboratory. After the visit students are asked to give presentation in a group of two students on each of the system studied during visit. After each of the presentation there was discussion and question answer session. These presentation are evaluated based on predefined rubrics which covers various aspects like knowledge gained, update on latest technology in that field, various design solution, presentation skill etc. Students were also asked to give feedback about self evaluation of understanding of the course on the scale of 1 (lowest) to 5 (highest). Technical quiz is also conducted to evaluate the performance of the students. Performance of these students (batch 2019) is compared with the previous batch (batch 2018) students for this course where there was no such activity was conducted. Attainment level of Course outcome and programme outcome is also evaluated and compared with the previous batch student. Course outcome is obtained through direct (Test 1, Test 2, End semester examination, quiz and presentation) and indirect assessment (feedback through Google form) tools.

\section{Results:}

As course is research oriented, visit to research laboratory helped students to understand the course in detail through experience. They understood research aspects in various topics in the course. Students have actually witnessed research experiment with liquefaction system and cryocooler. Presentation given by students based on this laboratory visit shows remarkable gain in their knowledge which is evaluated through direct and indirect assessment tools following rubrics for assessment. Knowledge sharing through presentation and discussion helped all the students to further increase their understanding of the course.

Effect of this learning method on Course Outcome is quantified from direct assessment tools (In semester: Test-1, Test-2, quiz, Tutorial and end semester examination). Course outcome (CO) is obtained from each of the assessment tool as mentioned in Table 1. Target set for each CO (total four CO) attainment is $60 \%$. Attainment of target in percentage is calculated as, $\frac{M}{N} \times 100$, where $\mathrm{M}$ is number of students scoring more than $60 \%$ marks in question pertaining to that $\mathrm{CO}$ and $\mathrm{N}$ is total number of students. Figure 1 shows comparison of \% attainment for year 2018 and
2019. For the same course no such activity was conducted in year 2018. Effect of this learning activity is seen on $\mathrm{CO}$ attainment. Except for $\mathrm{CO}-3$ there is considerable increase in all $\mathrm{CO}$ which is contributed to this learning activity conducted in year 2019.

Table 1: Contribution of different direct assessment tools towards CO attainment

\begin{tabular}{|c|c|c|c|c|c|c|c|}
\hline \multirow[t]{2}{*}{ CO } & \multicolumn{6}{|c|}{ Assessment Tool } & \multirow{2}{*}{$\begin{array}{c}\text { Avg. } \\
\%\end{array}$} \\
\hline & $\begin{array}{c}\text { Test } \\
1\end{array}$ & $\begin{array}{c}\text { Test } \\
2\end{array}$ & $\begin{array}{c}\text { Quiz } \\
1\end{array}$ & $\begin{array}{c}\text { Quiz } \\
2\end{array}$ & LAB & $\begin{array}{l}\text { End } \\
\text { sem. } \\
\text { Exam } \\
(\text { ESE) }\end{array}$ & \\
\hline $\mathrm{CO} 1$ & 86.36 & - & 100 & - & 85.06 & 90.91 & 90.58 \\
\hline $\mathrm{CO} 2$ & 65.91 & - & 27.27 & - & 84.73 & 79.55 & 64.37 \\
\hline $\mathrm{CO} 3$ & - & 56.82 & - & 54.55 & 88.52 & 59.09 & 64.74 \\
\hline $\mathrm{CO} 4$ & - & 79.55 & - & 45.45 & 86.25 & 61.36 & 68.15 \\
\hline
\end{tabular}

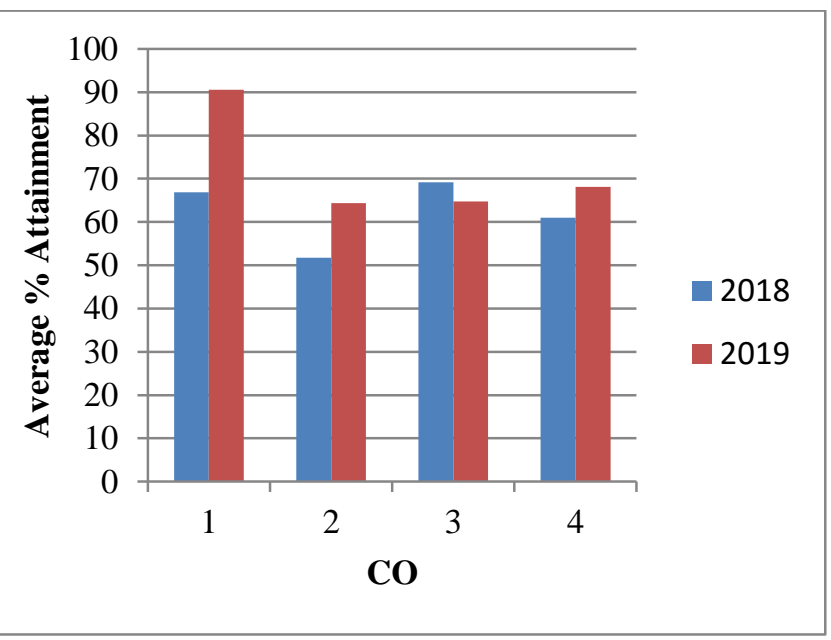

Fig. 1: Comparison of $\mathrm{CO}$ attainment for two consecutive years

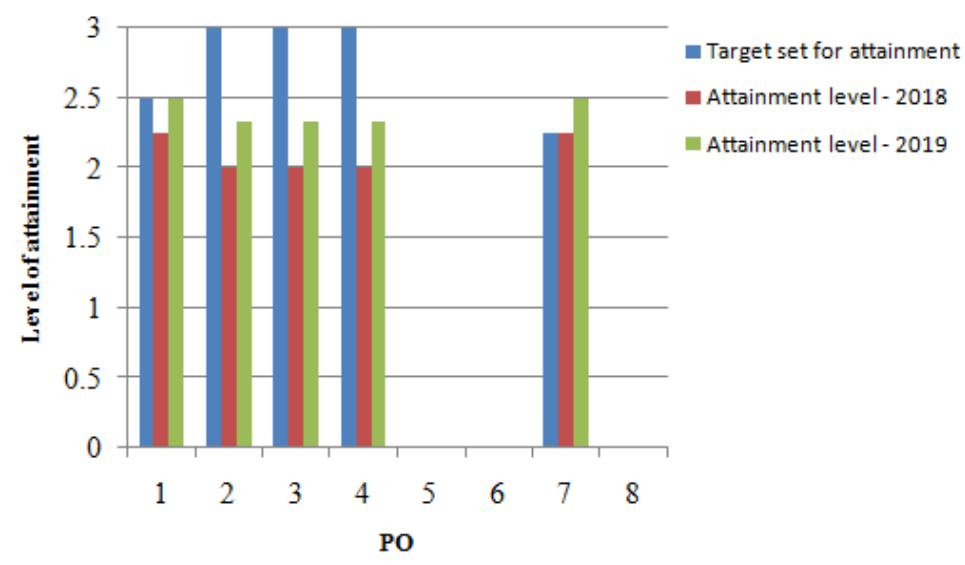

Fig. 2: Comparison of PO attainment for two consecutive year 
Course exit feedback is taken from student and estimated in \% for each $\mathrm{CO}$, based on response from students for questions asked pertaining to different $\mathrm{CO}$. Weightage of $80 \%$ is given to direct assessment tools and $20 \%$ to student feedback. Based on percentage average assessment, level is assigned to this attainment (Level $1-<60 \%$, Level $2-60$ to $69 \%$ and Level $3->70 \%$ ). Final level of attainment is calculated for each $\mathrm{CO}$ and further it is mapped with Programme Outcome (PO). Course is getting mapped with five PO (1, 2, 3, 4 and 7) out of 12. At the beginning of the course target is set for mapping of the course with the PO. Figure 2 shows comparison of PO attainment level for year 2018 and 2019. It has been clearly seen that PO attainment is increased for year 2019 as compared to 2018.

Visit to research laboratory presentation prepared based on these systems made them understand about approach to solve complex engineering problem through literature study, formulating problem, giving design solution and doing experiment to validate possible solution. Satisfaction level of student about research laboratory visit is quantified through feedback obtained through Google form as shown in Fig. 3. Figure shows that students are agree with the role of visit in improving their understanding of the course topics.

\section{To what extent visit to Cryogenics Lab at IIT helped you to understand liquefaction system}
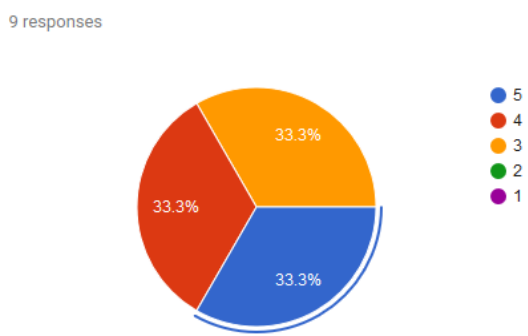

8. To what extent visit to Cryogenics Lab at IIT helped you to understand Cryo-cooler and its operation
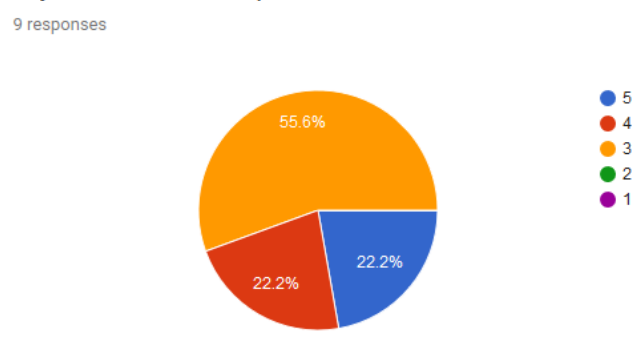

Fig 3: Students feedback about visit to research laboratory

\section{Conclusion}

From present study it has been found that experiential learning along with knowledge sharing help student to create interest in the course along with lifelong learning. Such active learning has increased academic performance of the student. Improved academic performance of the student is reflected in increase in Course Outcome as well as Program Outcome. In each course such active learning tools can be used which will make students more competent and Program Outcome can be successfully attained.

\section{Acknowledgement}

The author wish to thanks Prof. Milind Atrey (Professor, Mechanical Department, IIT Bombay) for granting permission to visit Cryogenic laboratory at IIT Bombay, Mumbai.

\section{References}

[1] Antonio L. Leal-Rodriguez, Gema Albort-Morant (2019) Promoting innovative experiential learning practices to improve academic performance: Empirical evidence from a Spanish Business School, Journal of Innovation \& Knowledge, Volume 4, Issue 2, Pages 97-103.

[2] Rebecca T. Sivarajah, Nicole E. Curci, Elizabeth M. Johnson, Diana L. Lam, Michael L. Richardson, (2019), A Review of Innovative Teaching Methods, Academic Radiology, Volume 26, Issue 1, Pages 101-113.

[3] P. C. Naga Subramanian, V. Iyappan, (2018), doi: 10.21839/jaar.2018.v3iS1.162.

[4] D. Kalyani and K. Rajasekaran, (2018), doi: 10.21839/jaar.2018.v3iS1.162

[5] Pavan Inguva, Daniel Lee-Lane, Anastasia Teck, Benaiah Anabaraonye, Wenqian Chen, Umang V. Shah, Clemens Brechtelsbauer, (2018), Advancing experiential learning through participatory design, Education for Chemical Engineers Volume 25, Pages 16-21.

[6] R. Dale Sheptak, Brian E. Menaker, (2016), Learning and working with the pros: Student perspectives on an embedded experiential learning project, Journal of Hospitality, Leisure, Sport \& Tourism Education, Volume 19, Pages 104-114.

[7] Fengfeng Ke, Sungwoong Lee, Xinhao Xu, (2016) Teaching training in a mixed-reality integrated learning environment, Computers in Human Behavior, Volume 62, Pages 212-220. 